\title{
¡CÓMO ESTÁ EL SERVICIO! EL SERVICIO DOMÉSTICO A TRAVÉS DEL CINE DE LOS AÑOS 60 EN ESPAÑA
}

\author{
How the Household Workers Are! The Household Work \\ Through the Cinema of the Sixties in Spain
}

\author{
Aritza Saenz Del Castillo Velasco \\ Universidad del País Vasco-Euskal Herriko Unibertsitatea \\ aritzasaenz80@hotmail.com
}

Fecha de recepción: 5-VI-2012

Fecha de aceptación: 31-VII-2012

\begin{abstract}
REsumen: El cine, como interpretación-representación de la realidad de un momento histórico determinado, refleja la mentalidad o corriente de opinión en torno a un periodo o respecto a un tema concreto dentro de él. Este artículo analizará la representación de las trabajadoras del servicio doméstico a través de la producción cinematográfica de los años 60 en Espańa. Dos películas, un drama y una comedia, nos servirán de vehículo para internarlos en la visión que del servicio doméstico poseían distintos sectores sociales, y su contraste con la realidad de las trabajadoras de este sector descrita por otras fuentes históricas.
\end{abstract}

Palabras clave: Cine, Franquismo, Mujeres, Servicio Doméstico.

АвSTRACт: Cinema, as interpretation and also as representation of the reality of an historic event, shows the thoughts and the opinion of certain facts in certain moment. This article will analyse the representation of the women household workers that appears in some films produced in Spain during the sixties of the twenty century. One, a comedy, and the other a drama, will help us seeing the point of view of different social classes about these women workers and the contrast between this reality and the reality described by other historical sources.

Keywords: Cinema, Franco's dictatorship, Women, Women Household Workers. 


\section{INTRODUCCIÓN METODOLÓGICA}

Como quedó claro a lo largo de las diferentes jornadas sobre «La historia a través del cine» organizadas por el Departamento de Historia Contemporánea de la Universidad del País Vasco-Euskal Herriko Unibertsitatea, las fuentes cinematográficas son un documento que invita a la reflexión acerca de la presencia del pasado en nuestras vidas. Son fuentes que van más allá de la mera "concepción de la historia como una acumulación de conocimientos sobre personas y acontecimientos de épocas anteriores a la nuestra, de las cuales no tenemos, ni podemos tener experiencia» ${ }^{1}$. En la búsqueda del conocimiento científico, y superando la dicotomía entre la aprensión de la «verdad» a través de la razón o de la experiencia, el séptimo arte se aproxima a los relatos del pasado mostrándonos las experiencias de la vida y así, desde un punto de vista empirista alejado de los postulados de formación francófila y de la metafísica alemana-Kant-, contribuye a ampliar el conocimiento de la Historia. El cine es el reflejo de una parte de la sociedad, de culturas, identidades y experiencias que nos ayuda a mejorar el conocimiento histórico sobre determinados procesos y acontecimientos del pasado.

Esta artículo se inserta dentro de las nuevas corrientes historiográficas que no descartan otras fuentes al margen de los documentos archivísticos, como las fuentes orales, literarias, y sobre todo las fuentes audiovisuales, etc., para la aproximación verosímil al pasado, a la realidad histórica, más si cabe teniendo en cuenta el extraordinario alcance e influencia del cine en la sociedad de masas del siglo XX y el creciente poder de la imagen dentro de ella ${ }^{2}$. Esta corriente de investigación ya consolidada liderada por sus propulsores Marc Ferro, Pierre Sorlin, Robert A. Rosenstone, Natalie Zemon Davies, acuñaron el término "historiofotografía» para describir las investigaciones históricas que parten de la fotografía para el estudio del pasado, y el cine como secuencia de fotogramas sería una herramienta eficaz dentro de esta corriente analítica, que vendrían a complementar el conocimiento de la tradición historiográfica prosaica aportando una interpretación original $^{3}$. Los filmes, a pesar de sus errores y arbitrariedades conscientes o inconscientes -que por cierto toda fuente puede tener-, mediante una metodología apropiada se constituyen en un documento histórico perfectamente útil para estudiar y conocer el pasado.

Partimos del hecho de que todas las fuentes son discursivas. Éstas se construyen con una intencionalidad y su análisis tampoco está carente de premeditación y subjetividad, despertada por el interés que muestra el investigador por un determinado tema, su manera de afrontarlo, y el fin que persigue con su estudio. El cine es otra fuente retórica más. Es una interpretación-representación de la realidad de un momento histórico

\footnotetext{
S. de Pablo, La historia a través del cine. Europa del Este y la caida del muro. El franquismo, Servicio Editorial de la U.P.V., Zarautz, 2000.

2 P. Burke, Visto y no visto. El uso de la imagen como documento histórico, Crítica, Barcelona, 2005.

3 M. Hughes-Warrington, The history on film reader, Routledge, New York, 2009.
} 
determinado, que refleja la mentalidad o corriente de opinión en torno a este periodo o respecto a un tema concreto dentro de él. Nos sirve de gran ayuda para entender las preocupaciones de una época, y siempre transluce la ideología del autor-director. Nos indican como pensaban las mujeres y hombres de una generación o la sociedad de una determinada época sobre un hecho histórico pretérito -o al menos como presupone el relator que sucedía-, más que profundizar en el acontecimiento histórico en sí. Las películas son testimonios de la Historia, pues como afirma el historiador Marc Ferro, son una construcción histórica, con mayor o menor acierto, que retrata a la sociedad de una época con amplitud, pues nos ilustra su modo de vivir, sentir, comportarse, de vestir, sus valores sociales, sus creencias, su cultura, e incluso su forma de hablar, etc. ${ }^{4}$, aunque sin voluntad de hacer un relato histórico profesional y verosímil que no compete al séptimo arte como tal. Esto significa que en ocasiones pecan de presentismo e introduzcen conceptos políticos, filosóficos, materiales o ideológicos, etc. anacrónicos y no existentes en la época que representan ${ }^{5}$. Por todo ello, y salvando estas particularidades, considero válidas las fuentes cinematográficas para la reconstrucción histórica y obtención del conocimiento de una época determinada.

\section{REPRESENTACIÓN DE LA IDENTIDAD FEMENINA A TRAVÉS DEL CINE FRANQUISTA}

La representación cultural como categoría de análisis nos permite indagar en la creación, fortalecimiento y declive de los diferentes discursos e identidades a ellos vinculados, tanto de género, como de clase, de etnia, de religión, de nación, etc. Esta representación es fruto del «consenso» que impone el discurso de poder en su proyecto de construcción social y política ${ }^{6}$. Todas las tendencias político-sociales tentadas de poder comprendieron la importancia de las artes, y sobre todo del cine, como herramienta idónea de difusión de su configuración de lo social ${ }^{7}$; más si cabe en un periodo y bajo un Estado de tendencia totalitaria, como el franquista, que aplicó la censura previa sobre

$4 \quad \mathrm{M}^{\mathrm{a}}$ A. Paz y j. Montero (coord.), Historia y Cine. Realidad, ficción y propaganda, Editorial Complutense, Madrid, 1995; A. Miguel Sáez de Urabain, Vitoria: imagen de una ciudad en calma. Una interpretación de las fotografías de Ceferino Yanguas como expresión de la sociedad vitoriana (19201949), Ayuntamiento de Vitoria, Vitoria, 2007.

5 J. Montero y A. Rodríguez, El cine cambia la historia, Madrid, Ediciones Rialp, 2005.

6 M. Nash, «Identidades, representación cultural y discursos de género» en Cultura y Culturas en la Historia, Ediciones Universidad de Salamanca, Salamanca, 1995, pp. 192-203.

7 En caso de la URSS está meridianamente claro en la obra V. Ilich Ulianov, Escritos sobre la literatura y el arte, Edicions 62, Barcelona, 1975; para el caso del fascismo italiano J. M. Claver Esteban, La pantalla nacional: El cine de la Italia fascista en la guerra, Quiasmo Editorial, Madrid, 2010; para el caso del III Reich D. Welch, Propaganda and the German Cinema, 1933-1945, Oxford University Press, New York, 1983 o H.L. Childs, Propaganda and Dictatorship, Princeton University Press, New York, 1936. 
toda manifestación cultural ${ }^{8}$, y en nuestro caso particular sobre guiones y secuencias de rodaje a través de la Junta Superior de Orientación Cinematografía y con la determinación de la curia eclesiástica y su Comisión Episcopal de Ortodoxia y Moralidad. La Orden de 21 de marzo de 1937 dejaba claro bajo qué parámetros tenían que confeccionarse las producciones cinematográficas si querían estrenarse: «en la labor de regeneración de costumbres» era preciso que el cinematógrafo "se desenvuelva dentro de las normas patrióticas, de cultura y de moralidad que en el mismo deben de imperar». Además contemplaban la potencialidad del cine en los siguientes términos: «El cinema futuro ha de ser, en primer término, un mensaje de la verdad española, una proclamación de nuestra belleza y de nuestra espiritualidad (...) El celuloide nacional habrá de llevar a los más distantes escenarios geográficos la emoción de una España real y viva (...) el arte tiene un puesto de primera línea. Porque el cinema es hoy el medio más eficaz de difusión y de propaganda...». De este modo las imágenes de las mujeres y los hombres presentes en las películas franquistas nos ilustran el sistema de géneros impuesto en dicha sociedad, imputando a cada sexo unas funciones y experiencias de vida determinadas. Al mismo tiempo estas representaciones cinematográficas reforzaron los modelos de género que reproducían, pues estos personajes transmitían un sistema de valores que en muchos casos era asumido e interiorizado por el público. A ello hay que sumar la importancia que tuvo el cine entre las trabajadoras del servicio doméstico, pues era uno de los más destacados pasatiempos donde invertían su jornada de descanso o su tiempo de ocio.

A lo largo del franquismo el ideal de la domesticidad femenina promovido por las distintas autoridades penetró en todos los ámbitos de la sociedad, y la identidad femenina fue circunscrita en torno a unas determinadas funciones biológicas y reproductoras $^{10}$. El séptimo arte no fue ninguna excepción, y en los largometrajes que reproducían la cosmovisión franquista -la mayoría de la producción española hasta bien entrada la década de los 60- los personajes representados por las actrices se centraban en la figura de esposas y madres y adquirían un papel secundario ${ }^{11}$. El principal protagonismo de las mujeres en la pantalla solía recaer en personajes célibes dedicadas a las artes-cantantes, bailadoras, cabareteras, actrices- que se veían envueltas en complejas tramas de amor. La figura de estas mujeres protagonistas «era confeccionada para ser contemplada y seducir

$8 \quad$ Estas tareas de control ejercidas por el régimen dictatorial del general Franco sobre el arte literario y la prensa son narradas en J. Gracia, Dionisio Ridruejo o el valor de la disidencia, Editorial Planeta Barcelona, 2007.

9 F. Sevillano Calero, Propaganda y medios de comunicación en el franquismo, Publicaciones de la Universidad de Alicante, Murcia, 1998.

10 Esta particular adscripción de las mujeres al futuro de la patria a través de su capacidad y calidad reproductora era compartida por los fascismos europeos.

11 R. Ruzafa, La historia a través del cine. Transición y consolidación democrática en España, Servicio Editorial de la U.P.V., Bilbao, 2004. 
la mirada del hombre» ${ }^{12}$. Aún siendo solteras, el objetivo que caracterizaba a muchas de ellas giraba en torno a la búsqueda de un novio, amorío que si concluía con éxito, desembocaría en el casamiento y la formación de una familia. Para que este fin último de todo personaje femenino fuese alcanzado y tuviera fortuna, hombres y mujeres debían cumplir los roles asignados por la ideología franquista, que no eran otros que la humildad, la modestia, la pureza y la castidad, tanto física como moral de las mujeres, y su subordinación a la figura masculina ocultada bajo el influjo del amor romántico. Así la vanidad, el capricho, la frivolidad, el carácter pronunciado y la autonomía femenina con frecuencia eran castigas en la pantalla con un destino trágico o sufrido ${ }^{13}$. Esta construcción de la feminidad adquirió rasgos nacionalistas, pues este modelo de mujer «virginal» era identificado generalmente con el carácter de las mujeres españolas, en contraposición a la representación «perversa» de las mujeres extranjeras. En lo que respecta al hombre, la virilidad fue uno de sus máximos exponentes y era representada de varias maneras: a través del vigor y la fortaleza física, la galantería, la figura de mujeriego con tintes donjuanescos -la sexualidad como atributo de la masculinidad-, el cabeza de familia responsable en exclusiva de la economía de la unidad doméstica, etc. Valga como referencia el artículo titulado "Las cualidades y virtudes que una mujer debe buscar en el hombre» publicado en la revista Nuestra Casa (N.C.) en septiembre de 1960: «...Igualmente se debe buscar en el hombre que sea trabajador y sano, pues lógicamente él tiene que traer el sustento a la casa, y un hombre vago y enfermo será, en vez del cabeza de familia, una carga para la mujer, que tendrá muchas veces que hacer de padre y madre con los hijos y trabajar fuera de casa para sacar adelante su hogar..."

Este discurso de género, que otorgaba a las mujeres la función social de la maternidad y el cuidado familiar y a los hombres la figura del ganador de pan o sostenedor económico de la unidad doméstica, delimitaba el radio de acción de éstas al estrecho cerco del hogar y conceptualizaba el trabajo extradoméstico de las mujeres como un atentado contra su femineidad; a su vez, su participación laboral extradoméstica y el consiguiente abandono del hogar, era concebido como un peligro que acechaba la existencia de la familia tradicional cristiana, eje fundamental de la sociedad franquista, y en nombre del «falso progreso social» les acercaba más «hacia el abismo socialista» ${ }^{14}$. Por ello el ordenamiento jurídico de la dictadura, en su primera ley fundamental de 1938 -El fuero del Trabajo que estuvo vigente durante todo el franquismo-, sentenciaba entre sus objetivos grandilocuentes «libertar a la mujer casada del taller y de la

12 Para un estado de la cuestión sobre la representación femenina a través de la imagen y su análisis feminista, N. Ardanaz Yunta, "Cría cuervos, La representación del universo femenino en una película de la transición» en R. Ruzafa, La historia a través del cine, op. cit.

13 En los cuentos y relatos insertos en la revista Nuestra Casa las mujeres con estos caracteres no se casaban jamás.

14 A. García de la Granda, «Legislación social y legislación socialista», en Revista de Trabajo, Madrid, Noviembre-Diciembre 1950. 
fábrica»; el posterior desarrollo de distintas leyes laborales perseveró en la sanción de su participación en trabajos extradomésticos (Excedencia forzosas, plus familiar, trabajos peligrosos,...). Las obras moralizantes de origen religioso también subrayaban el peligro que suponía para las mujeres el abandono del hogar y su inserción en la actividad productiva -Enciso Viana, Chombart-; incluso las obras de divulgación científica compartían esta visión -Marañon, Lpz. Ibor, Bosch Marín, Iserte-. Todo ello incidió en la invisibilización de estas prácticas laborales femeninas tanto en las fuentes de cuantificación como en la literatura y el cine. El mundo laboral femenino extradoméstico no atrajo el interés de las artes, y si era representado, frecuentemente era bajo una mácula de negatividad -necesidad, capricho- ${ }^{15}$.

Sin embargo los trabajos relacionados con el ámbito del hogar despertaron mayor interés, ya que eran considerados apropiados para el desarrollo íntegro de las mujeres y una escuela de aprendizaje útil para formarlas ante su futura misión en su propia familia. Así la representación laboral de las mujeres en la novela, el teatro y en la pantalla se centró básicamente en las trabajadoras del servicio doméstico. Debido a la informalidad del sector que generó escasa documentación archivística relacionada con esta actividad, estas fuentes resultarán de gran utilidad. Respecto a la novela realizada durante nuestro periodo de estudio tenemos varios ejemplos. Desde el realismo preñado de crítica social de Juan Marsé, que en Últimas tardes con Teresa describe a través de la novia y la madre del protagonista las vicisitudes de las muchachas del servicio domestico. Otra obra que concede protagonismo a las trabajadoras del servicio doméstico es Fragmentos de interior de Carmen Martín Gaite. Esta novela de carácter íntimo entrecruza varias historias a través de las relaciones de los empleadores con su empleada de hogar.

En las representaciones cinematográficas del primer franquismo las trabajadoras del servicio doméstico protagonizaron personajes secundarios, y la profesión distó de ser el hilo argumental de los filmes. Esto cambiaría en la década de los 60, cuando el servicio doméstico centró buena parte del interés de la opinión pública, con pareceres encontrados. A lo largo de estas páginas abordaremos esta visión particular que nos ofrece el celuloide de la época del desarrollo y del tardo franquismo en torno al servicio doméstico, sus trabajadoras y su especial evolución.

15 F. Gil Gascón, Construyendo a la mujer ideal: mujer y censura cinematográfica durante el franquismo (1939-1963), Universidad Complutense de Madrid, Madrid, 2010, p. 107. Esta afirmación hay que matizarla e introducir la excepción que representa la fotografía, pues los profesionales locales como Ceferino Yanguas, Arque, y Schommer retrataron con sus cámaras la actividad femenina en la industria vitoriana y en el agro alavés durante la década de los 40, 50 y 60 del siglo XX. En una etapa precedente, finales del XIX y primeros veinte, ya lo habían hecho los lienzos costumbristas de Ignacio Díaz de Olano. 


\section{CONTEXTUALIZACIÓN HISTÓRICA DE LAS PRODUCCIONES CINEMATOGRÁFICAS}

El fuerte desarrollo económico que experimentó España en la década de los 60 del siglo XX hizo que la sociedad entrase en vías de modernización. El mundo urbano adquirió protagonismo sobre el mundo rural, que poco a poco salía de su letargo a través de la reorganización, racionalización y la mecanización. El aumento de la productividad agraria supuso un remanente de mano de obra, que atraída por la idea de progreso que irradiaban las urbes en continuo crecimiento industrial y de sus servicios, provocó grandes flujos migratorios que incluso sobrepasaron las fronteras españolas. Mujeres y hombres salieron de sus pueblos con destino a las ciudades en busca de una ocupación con que mejorar su situación personal y familiar ${ }^{16}$. Tradicionalmente la inmigración femenina se solía colocar en el servicio doméstico, que durante la posguerra española atravesó una época dorada. Pero el "progreso económico» abrió las puertas de otros sectores productivos a las mujeres, pues la necesidad de mano de obra era perentoria.

El sistema político para adaptarse a esta nueva coyuntura de expansión económica y granjearse el reconocimiento de su democracia orgánica en las instituciones internacionales, de las que ya formaba parte en el plano económico, pero no en el político, comenzó un ligero aperturismo social. En lo que respecta a las mujeres, en 1961 promulgó la ley sobre los derechos políticos, profesionales y de trabajo de las mujeres que eliminaba parcialmente la discriminación social y laboral que venían padeciendo «basadas en situaciones sociológicas que pertenecían al pasado y que no se compaginaban ni con la formación y capacidad de la mujer española ni con su promoción evidente a puestos y tareas de trabajo y responsabilidad». A lo largo de la década fue tomando cuerpo la ley de Asociaciones, que en 1968 impulsó la creación de las asociaciones de las amas de casa y su socialización y protagonismo en la esfera pública. Esta tendencia aperturista y el protagonismo social y político de las mujeres se consolidó ese mismo año, al reconocérseles el derecho de ser electoras y elegibles de la representación del tercio familiar, uno de los pilares básicos del sistema político franquista junto al municipio y al sindicato, que había estado hasta entonces en manos de los cabezas de familia varones.

El turismo, fuente de divisas y motor de la recuperación económica, introdujo nuevas ideas, costumbres y comportamientos, que tuvieron impacto en la mentalidad y la cultura de los españoles. La moral tan estricta impuesta en los ańos más duros del nacional-catolicismo comenzó a disolverse y contribuyó a romper con la adscripción de las mujeres al hogar, posibilitando que su trabajo extradoméstico se librase de tantos prejuicios y connotaciones negativas. De este modo las mujeres aumentaron su participación en la industria, y sobre todo en el sector terciario (secretariado, administración, comercio). Esto provocó que la demanda de mano de obra en el servicio doméstico fuese

$\overline{16}$ R. Tamames, Introducción a la economía española, Alianza Editorial, Madrid, 1998. 
muy superior a la oferta, y que las clases medias comenzaran a profetizar lo que podía ser el final de este mercado laboral tan particular. Se originó un debate de cierta importancia en la sociedad en torno al servicio doméstico. La polémica saltó a las planas de los principales diarios, donde se imprimieron discusiones acaloradas respecto a su posible reglamentación y la tan traída y llevada controversia sobre la capacitación de las trabajadoras de este sector y el salario que debían percibir o exigir.

En este periodo de la historia de Espańa, cuando el servicio doméstico deja de tener la primacía dentro del mercado de trabajo femenino, pues las mujeres empiezan a ocupar masivamente otros sectores laborales, es cuando se le presta mayor atención con obras monográficas dentro del cine ${ }^{17}$. Todo el entramado argumental de estos filmes giraba en torno a esta profesión, y más exactamente sobre las vidas y las peripecias de las trabajadoras del servicio doméstico. Analizaremos dos películas de la producción cinematográfica de este momento y pertenecientes a diferente género, como son «Como está el servicio», comedia dirigida por Mariano Ozores en 1968, y el drama titulado «Españolas en París» de Roberto Bodegas producido en 1971, que mostrarán el distinto tratamiento de las trabajadoras del servicio doméstico. Hemos elegido estos filmes pues aparte de pertenecer a géneros diferentes, también son representativas de dos concepciones contrapuestas de hacer cine. La primera podemos adscribirla dentro de las comedias «irritantes y grotescas a la española» que inundaron las salas de proyección en la década de los 60 (ABC 28-11-1968). Esta corriente denominada «landismo», dentro de la cual Ozores es uno de los máximos exponentes, englobaba a un cine comercial carente de crítica y de motivaciones socio-políticas, que a través de la risa fácil y aderezada con una dosis de erotismo - presencia de faldas cortas, escotes pronunciados...-, caricaturizaba los estereotipos y tópicos socialmente aceptados. «Españolas en París» por el contrario, se enmarca dentro de la corriente cinematográfica denominada tercera vía, representada entre otros por los directores Roberto Bodegas y José Luis Dibildos, que procuraron realizar un cine híbrido entre el oficial-comercial y el cine de autor con base reivindicativa y de orientación crítica ${ }^{18}$. Eran reflejo de la sociedad del consenso que se vertebraría en la etapa preconstituyente.

En estos dos largometrajes participan un elenco de actores españoles característicos del cine y la televisión desarrollista española que asegurarían una buena acogida de público, y que hace que acreciente nuestro interés por su estudio, pues pueden ser representativas del cine de masas de una época.

17 "Chica para todo» de Mariano Ozores de 1962; "Las que tienen que servin» de José Ma Forqué de 1967; "El señor está servido», de Sinesio Isla de 1975.

18 L. Navarrete, La historia contemporánea de España a través del cine español, Editorial Síntesis, Madrid, 2009, p. 239. 


\section{SINOPSIS CINEMATOGRÁFICA}

Mariano Ozores en "Como está el servicio» adapta la obra teatral homónima de Alfonso Paso a la gran pantalla. Narra la historia de una mujer joven de origen rural, Vicenta Berrugillo Tolomé, que abandona su pueblo cacereño para dirigirse a Madrid y emplearse en el servicio doméstico. Allí le aguarda su primo que es el encargado de buscarle las casas donde colocarle. La carrera profesional de Vicenta es un tanto movida, pues permanece poco tiempo en cada domicilio. Al inicio trabaja consecutivamente en la casa de dos mujeres espańolas de origen moralmente dudoso casadas con militares estadounidenses de la base de Torrejón. Al observar el oscuro pasado de estas dos mujeres y considerar que no es una casa decente decide plantarlas y su primo le busca otras casas donde trabajar. Vicenta vuelve a desistir por voluntad propia pues no le gustan sus nuevos destinos.

Este trajín de idas y venidas le produce a Vicenta cierto desasosiego. Aquejada de nervios acude a una consulta médica. Observa que la casa está en un completo desorden, que es achacado a las jaquecas que sufre la madre del facultativo y a la ausencia de la trabajadora del servicio doméstico que recientemente se despidió. Ella se ofrece para suplir la baja, a lo que el médico y su familia acceden. Vicenta se enamora del médico y éste a requerimiento de su padre le sigue el juego y comienza a seducirla, con el fin de mantener a la criada el mayor tiempo posible. Posteriormente el médico alentado por su conciencia confiesa a Vicenta el engaño amoroso que ha urdido su familia. Ésta airada abandona el hogar, pero posteriormente el médico se percata de haberse enamorado y deciden casarse.

Paralelamente a esta historia principal protagonizada por Vicenta, se escenifican las andanzas amorosas y engañadizas de su primo que seduce a 8 mujeres con falsas promesas de matrimonio. La mayoría de ellas son trabajadoras del servicio doméstico. Les extrae ciertas cantidades de dinero, aprovechándose de la ilusión de éstas por la adquisición de una vivienda donde realizar la futura vida conyugal de ambos. Finalmente es descubierto por todas ellas, que se unen para darle un ejemplar escarmiento.

Roberto Bodegas a través del drama "Españolas en Paris»cuenta la experiencia migratoria de la juventud española. El hilo conductor será la historia de una joven adolescente, que permitirá ilustrar el desenvolvimiento de toda una generación. La protagonista, de nombre Isabel García Laguna, emigra de Sigüenza a París donde le espera Emilia, paisana que ya le ha buscado colocación de sirvienta en una familia. En el desarrollo de su oficio entra en contacto con otras trabajadoras del servicio doméstico españolas, con las que entablará una profunda amistad. Una de ellas es Francisca, que a su llegada llevaba 5 meses residiendo en París, pero al no adaptarse al ritmo de la urbe termina regresando a España. Dionisia es otra de sus amigas sirvientas, que tras tres ańos de 
noviazgo, emigró a París con intención de hacer unos ahorros con los cuales afrontar su casamiento; su novio con idéntica estrategia emigró a Stuttgart. La propia Emilia llevaba 5 ańos en París colocada como empleada de hogar. Emigró en viaje de novios en compañía de un hombre casado de Sigüenza que le prometió que dejaría a su mujer y se casaría con ella por lo civil en el país de la libertad. Cuando se acabó el dinero, él se volvió a Sigüenza y su mujer le perdonó. Ella sin embargo se quedó sola en París, ya que al pueblo no podía volver por la fama perversa que recaería sobre ella. Emilia compaginaba su jornada laboral con flirteos amorosos poco corrientes. Buscaba hombres españoles con quienes iniciar una relación y ante los cuales se hacía pasar por adinerada francesa contratante de servidoras domésticas. En el transcurso de la película iniciará dos relaciones amorosas simultáneas, una con un economista llamado Fernando, y otra con Plácido, administrativo de una empresa española, ambos comprometidos sentimentalmente en España. Excepto Emilia, todas conciben su estancia en París como algo eventual, tras lo cual volverán a España. Estas emigrantes se reúnen con frecuencia.

Entretanto Isabel inicia una relación de amistad con Manolo, un emigrante español que lleva dos años trabajando como chofer y criado en la misma casa que Emilia. Pese a las advertencias y la desaprobación de ésta, la amistad persiste y terminará desembocando en un embrollo amoroso que culminará con el embarazo de Isabel. Manolo, pese a tener novia formal en España, en un primer momento decide asumir su responsabilidad. Le propone como solución el abortar, pero Isabel se muestra dubitativa y en el último instante lo rechaza enérgicamente. Continúa con su embarazo de forma independiente y reconduce su amistad con Emilia, que abandonó el servicio doméstico para colocarse en una clínica veterinaria. A su vez Isabel cambia de profesión y se coloca como empleada de unos almacenes. Finalmente dará a luz a un hijo que le llamará como a su hermano, Andrés García Laguna.

\section{REPRESENTACIÓN DE LAS TRABAJADORAS DEL SERVICIO DOMÉSTICO EN EL CINE DE LOS 60}

Ambas películas destacan el origen emigrante e eminentemente rural de las trabajadoras del servicio doméstico. Tanto Vicenta como Isabel arriban a la capital desde sendos pueblos de provincia y se las ve bastante perplejas ante su nuevo destino. Desconocen los nuevos ritmos de vida de las ciudades y muestran inicialmente dificultades de adaptación que pronto son superadas. El proceso migratorio de estas jóvenes no es individual y cuentan con intermediarios - primo de Vicenta y Emilia- que les facilitan la llegada y la inserción laboral. Éstos serán los responsables de pactar las condiciones laborales con los empleadores, donde las trabajadoras no intervienen en ningún momento. 
Las protagonistas son jóvenes solteras con escasa cultura, lo que quedará patente en varias ocasiones a lo largo del desarrollo fílmico. Vicenta apenas sabe las primeras letras y las cuatro reglas e Isabel justo terminó la primaria abandonando la escuela a los 13 años. Esta deficiencia formativa es asociada con frecuencia a la ignorancia, que en la película de Ozores es empleada como recurso cómico, no así en la película de Bodegas. Éste le otorga a la instrucción académica un valor capital y en ocasiones Isabel se lamenta no haber estudiado. Aún así, a lo que a la educación se refiere, los modelos de género de la Espańa franquista están muy presentes. La educación de las mujeres tiene poca importancia en el seno de las familias y se prima la de los hombres - «las mujeres al fin y al cabo con saber un poco, pero un hombre si no tiene estudios ${ }^{19}{ }_{\eta-}$. Así en Españolas en París observamos cómo Isabel y su hermana se sacrifican trabajando para contribuir económicamente al sostenimiento de la familia, y posibilitar los estudios superiores y universitarios de su único hermano varón Andrés. La promoción social de la familia se concentra en manos de los descendientes varones.

Esta ignorancia en la esfera cultural también es reflejada en la esfera profesional. En los primeros momentos, cuando entran en contacto con la familia a que van a servir, las trabajadoras del servicio doméstico son representadas como absolutas desconocedoras del oficio y de cualquier tarea relacionada con el servicio doméstico; también desconocen los modales y comportamientos básicos exigidos por sus empleadores. En el caso de Vicenta es escenificado en la secuencia que planchando unos pantalones del señor termina quemándolos y en un primer plano sirviendo la mesa. Por su parte la situación de Isabel requiere mayor complejidad de análisis, pues a la dificultad del idioma por comprender a sus empleadores, se suma la diferencia tecnológica existente en la capital francesa respecto a España. Aun así, Roberto Bodegas cuestiona esta primera impresión de incapacidad profesional, y la achaca a la propia cosmovisión que tienen los empleadores sobre sus empleadas. En una escena en que se saltan los plomos, el cabeza de familia se mofa de Isabel porque se piensa que reza ante la sorpresa de quedarse sin electricidad, pero en realidad lo que está es pendiente de la cocción de unos huevos.

Pese a esta descualificación inicial descrita, los dos personajes enseguida muestran su capacitación para el oficio. Mariano Ozores no repara en este proceso de aprendizaje, pero Bodegas sí. Éste lo asocia a la labor pedagógica ejercida por la empleadora, que muestra interés en formar a la empleada en los gustos y apetencias de los contratantes. Esta atención y apoyo sobre la empleada de hogar, según la película, es impulsado desde el falso paternalismo que busca el racionalismo económico, con intención de aumentar su productividad y disminuir los conflictos de clase. La forma correcta de atender las llamadas telefónicas y la recepción de los recados representan en ambas películas la cúspide de este proceso aleccionador.

$\overline{19}$ Frase entresacada de un diálogo de Isabel con Manolo. 
Las trabajadoras del servicio doméstico son constantemente infantilizadas, a pesar de ser personas en edad de trabajar y ser económicamente independientes. Esta característica es extensible a todas las mujeres, y queda bien reflejada en la apreciación que el primo de Vicenta hace de ellas: «las mujeres no son mayores de edad hasta los 50». Tanto Vicenta como Isabel están bajo la tutela de una tercera persona -su primo y Emilia-, quien guiará todos sus actos y será responsable ante la familia de éstas. Esta característica hace que sean concebidas como personajes altamente corruptibles y fácilmente manipulables, especialmente ante las actitudes zalameras de los hombres. Siguiendo los preceptos de la moral de la época, los varones son identificados como el mayor peligro que acecha a estas mujeres solteras y a su valor más preciado, la virginidad. Tanto el primo de Vicenta como Manolo representan a dos personajes mujeriegos. Uno a largo de la película está envuelto en amoríos simultáneos con diferentes empleadas de hogar y camareras; al mismo tiempo figura como el valedor moral de Vicenta, que cuida de que no le "quiten el refajo» y de que «vuelva a Villarioso siendo mujer». La actuación de este personaje discurre en un ambiente cómico, que asume plenamente y sin crítica el comportamiento y los desmanes del «macho español» ante las despersonificadas sirvientas. Manolo a su vez engaña a Isabel con falsas esperanzas de ruptura con su novia formal y el posterior casamiento con ella; nada de ello ocurre, pero sin embargo pierde la virginidad con él. Roberto Bodegas mediante la muy meditada simbología - la reproducción de la Marsellesa mientras transcurre la escena de cama que dejará embarazada a Isabel, la alusión de Emilia al matrimonio civil, besarse apasionadamente delante de un gendarme- arremete contra los modelos de libertad moral, civil y sexual presentes en Francia por pervertir a la «mujer espańola», crítica que llegará al paroxismo en la escena del aborto. Esta actividad contraceptiva es representada bajo técnicas y formas pasadas cercanas a la brujería y muy lejos de las prácticas médico-científicas desarrolladas en estos países europeos. Aún así no reprueba con contundencia -lo hace ligeramente- la actitud de Manolo, que al fin y a la postre es junto a Isabel el responsable directo de la «perversión».

Ozores retrata una historia de amor romántico, donde la diferencia de clase no es óbice para que Vicenta obtenga la considerada meta de toda mujer, el matrimonio, como recompensa a su intachable moralidad. Este ideario está resumido en la frase que el médico le dedica: «Vicenta, tú has nacido para casarte». Este objetivo último asignado al género femenino estaba muy presente en la sociedad española y fuera de ella. Representan como natural e innato el casamiento y la construcción de una familia. Así el resumen de la película «El albergue de la Sexta Felicidad», donde Ingrid Bergman protagonizaba a una sirvienta que se mete a misionera concluye, «Un hogar y un hombre que la quiere de verdad, Gladys ha terminado su misión $»^{20}$. Mariano va más allá y desprecia a las esposas que no encajan con el ideal de la domesticidad y sus funciones. Asume como normal que

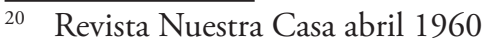


un hombre veje a su esposa e incluso la amenace por no saber realizar las tareas domésticas que exige el cuidado de una familia.

A diferencia de Ozores, Roberto no sucumbe en el destino final y manifiesto de toda «mujer espańola», el matrimonio. La protagonista rechaza el aborto enérgicamente y apuesta conscientemente por la condición de madre soltera, que le permitirá vivir con orgullo -registro de su hijo Andrés en la embajada española-, independencia, e incluso promocionar profesionalmente. Representa a la madre soltera como un ser realizado, modelo contrario al persistente todavía en algunos reductos de la sociedad espańola, ideario del cual Isabel era portadora pero que logra superar.

En estas películas existe una diferente exaltación de la españolidad. La representación de España como baluarte de la moralidad cristiana y femenina frente a las culturas lascivias extranjeras es un hecho constatado en ambas películas. En la película de Ozores, los hogares encabezados por cabezas de familia estadounidenses, son hogares que contrastan con los espańoles por su falta de moralidad. Sus esposas son identificadas como prostitutas o mujeres de buen vivir. Como dijera Camilo Alonso Vega, director de la Guardia Civil y ministro de la gobernación, «la mejor aportación que han hecho los americanos es limpiarnos de curritas los bares y los cabarets de Madrid, pues casi todas se casan con sargentos y soldados» ${ }^{21}$.

Este pensamiento era compartido por las tradicionales clases acaudaladas y aristocráticas, que rechazaban a estas nuevas familias pudientes de origen plebeyo y extranjero. Uno de los aspectos que ahondaba en esta marginación resultaba ser el mayor poder adquisitivo y la mayor facilidad de atracción de las trabajadoras del servicio domestico, ya de por sí escasas. La imposible competencia con el poder de atracción de los dólares les irritaba profundamente y debían incurrir en otros aspectos, como el ataque moral y el desprestigio cultural presente en esta proyección, para rivalizar en la búsqueda de mano de obra. Así lo retrata Ozores en la secuencia en que Engracia La Cajetilla, ya esposa del militar americano, subraya la distinción de trato ante Vicenta y enfatiza en su designación y reconocimiento como señora, "el señora que suene muy alto", para remarcar su falso origen señorial; o en aquella otra escena que hablando de China y la revolución de Mao, Engracia piensa en un gato. Ozores lo afronta desde el prisma cómico, pero no por ello deja de ser una crítica a los norteamericanos y sus esposas, denuncia muy presente en los artículos de opinión de los principales diarios de ámbito nacional. Así ABC durante la década de los 50 y los 60 reprobó en numerosas ocasiones la actitud de los estadounidenses como usurpadores de la mano de obra española destinada al servicio doméstico, y se resume en la siguiente frase: «No se donde vamos a llegar con esos americanos que les ofrecen el oro y el moro por no hacer nada...» (Blanco y Negro 31-8-1957).

$\overline{21}$ J. Eslava Galán, De la alpargata al seiscientos, Editorial Planeta, Barcelona, 2010, p. 67. 
Como quedara dicho anteriormente Roberto Bodegas también asociaba la espańolidad con la defensa de la moralidad cristiana y sus prácticas religiosas. Así las dos jóvenes sirvientas -Paca e Isabel-acuden a misa los domingos, en contraste con la actitud de Emilia que afrancesada en apariencia -se hace pasar por francesa- no cumple con los preceptos religiosos. La religiosidad de las sirvientas fue un aspecto que se cuidó mucho y al que se le prestó especial atención durante la década desarrollista. Desde las páginas de la revista N.C., en su sección fija "Cristo en tu vida» se imploraba constantemente a que acudiesen a misa una vez por semana, y que participaran en ella de forma activa y consciente.

Pero Roberto Bodegas también muestra retazos de exaltación patriótica desde el punto de vista de la emigración y su importancia económica. Tenemos una escena donde después del partido de fútbol que enfrenta a la selección española contra la francesa, un espańol se encarama a un coche de marca gala, y le empieza a recriminar que está hecho por él y que por tanto también tiene que ser español. Ilustra la idea de cómo el trabajo de los españoles contribuye al desarrollo y la riqueza de otros países, en menoscabo de su propia nación. Aunque también reconoce a través de las declaraciones del economista que los emigrantes también contribuyen al desarrollo del país mediante la importancia de las divisas. Este patriotismo económico es contradictorio y encaja muy bien en la mentalidad del desarrollismo. Por un lado veía la emigración con recelo, pues en muchos casos se llevaba a los trabajadores más formados y los empleaba en puestos que no contribuían a su cualificación profesional -representado por las figuras de Manolo y Emilia, fresador en la Barreiros y administrativa respectivamente, y en París ambos servidores domésticos-. Al hilo de esta desvalorización de la mano de obra española, que no depreciación pues cobraban más como sirvientes, hace una crítica de la ley francesa respecto al tratamiento de los trabajadores emigrantes, ya que son colocados en los peores puestos; pero por otro la emigración era una válvula de escape en momentos de desempleo creciente y su aportación resultaba clave para financiar la modernización del país y equilibrar la balanza de pagos. Finalizando con la representación de la emigración como manifestación patriótica, su repatriación es identificada en numerosas ocasiones -la vuelta de Francisca y Dionisia- con la felicidad y se opone a que nuevos españoles, el caso de la hermana de Isabel, inicien el mismo duro proceso de desplazamiento.

El desarrollo económico superior de Francia respecto a España es aprovechado por Bodegas para resaltar nuevamente el amor o orgullo patrio. En la escena en que se saltan los plomos representa a los franceses como personajes con aires de superioridad y que poseen una idea preconcebida de los españoles como un pueblo atrasado, subdesarrollado e ignorante, que él niega mediante el conocimiento de Isabel.

Estos estereotipos de lo español frente a lo extranjero, muestran la preocupación que poseen ambos directores por la identidad cultural propia, que ven amenazada tras el 
aperturismo producido en la década de los sesenta. La representación opuesta del otro frente al yo, consciente o inconsciente pero presente en ambas películas -la cultura exótica frente a la hispánica-, tanto en el plano moral, religioso o económico, es una de las manifestaciones y reacciones típicas que contempla Peter Burke cuando un grupo social se enfrenta a otras culturas ${ }^{22}$.

\section{CONCLUSIONES}

La representación de las trabajadoras del servicio doméstico presente en ambas películas está construida basándose en tópicos y son muy generalizadoras. Primeramente sólo escenifican el servicio doméstico tradicional representado por las trabajadoras internas, modalidad que estaba en claro retroceso en la España del desarrollo, frente a la proliferación de las interinas, que apenas son nombradas en una ocasión. Unido a ello las trabajadoras del servicio doméstico que visionamos en estas películas son jóvenes, que concluyen su actividad cuando contraen nupcias. Esta imagen distorsiona los datos procedentes del Montepío del Servicio Doméstico, que en sus previsiones poco halagüeñas sobre la viabilidad de la entidad, subrayaban el cada día mayor peso y presencia de las trabajadoras mayores cercanas a la jubilación. Siguiendo con las uniformidades muestra a las trabajadoras del servicio doméstico como personajes asistidos en la emigración y con poca iniciativa personal en este proceso. Esta clasificación contrasta con el interés que las autoridades tanto civiles como eclesiásticas mostraron por este colectivo, que según describían llegaban a las ciudades desamparadas y sin ningún contacto que les facilitase la inserción en la vida y costumbres de la urbe. Para socorrerles y también en defensa de cierta moralidad, impulsaron legislaciones y proyectos de acogida, lo que demuestra que sí fueron agentes activos en la emigración, e incluso en ocasiones fueron las pioneras de este proceso que facilitó la posterior llegada a las ciudades de otros miembros de la familia ${ }^{23}$.

Otra de las representaciones apriorísticas que caracteriza al servicio doméstico en estas películas es su desconocimiento de la profesión al llegar al mundo urbano. Puede que en algunos casos fuese así, pero en otros se intentó poner remedio a esta descualificación profesional a través de la constitución en diferentes núcleos rurales de Escuelas de Hogar que las capacitarían para el trabajo. Además muchas de las mujeres dedicadas al servicio doméstico ya habían trabajado con anterioridad en el sector en sus respectivos pueblos o lugares de origen. La propia familia también actuaba como medio de aprendizaje de las tareas a desempeñar en el hogar, pues las hijas, sobre todo las mayores, tempranamente

22 P. Burke, Visto y no visto, op. cit. pp. 155-156.

23 C. Borderías, «Las mujeres, autoras de sus trayectorias personales y familiares: a través del servicio doméstico», Historia y Fuente Oral, n6, 1991, pp. 105-121. 
debían hacerse cargo de estos quehaceres -lavar, planchar, cuidar de los hermanos pequeńos, etc. - como así quedó reflejado en «El diario de una muchacha de servir» publicado en la revista N. C. de agosto de 1960. Más bien esta aparente descualificación proviniera de la difícil adaptación a los diferentes gustos de cada empleador, pues si no es incomprensible la rápida progresión de que hacen gala. Nuevamente «El diario de una muchacha de servir» arroja luz sobre este punto: «...Pasé una semana terrible. No sabía donde tenía la cabeza. Todo eran órdenes nuevas y consejos. Yo creí que sabía planchar y lavar muy bien y resulta que la señora se empeñó en decir que no, que no y que no (...) No, Catalina ¿Pero no ves que ese cuello de la camisa está lleno de arrugas? (...) Catalina, las toallas no se retuercen nunca así (...) Así sucedió con todo...» pero la empleadora en su perseverancia en enseñarle sus preferencias exclamaba «Ten paciencia. Estoy segura de sacar de ella una buena muchacha. Ya va aprendiendo». Por otra parte, esta descualificación puede tener origen en la eterna cosmovisión que representa el mundo rural como un espacio atrasado e ignorante, que es contrapuesto al dinamismo de las ciudades, que en el desarrollismo franquista cobrará nuevo impulso.

Aparte de estas similitudes, estamos ante dos ideas o representaciones muy distintas del servicio doméstico. Mariano Ozores afronta su puesta en escena desde unos preceptos ideológicos propios de parte de la burguesía y de la clase media que retratan la profesión desde un prisma externo; se trata de una mirada poco acorde con los cambios y el impulso modernizador de otra parte de las clases medias profesionales. Pese a ser las principales protagonistas de los guiones, no reparan lo más mínimo en la vida y los problemas cotidianos de estas trabajadoras -quizá una comedia tampoco deba hacerlo-. Por el contrario sí se preocupa en escenificar la escasez de mano de obra en el sector y la dificultad que tienen los empleadores en encontrarla. Visión en concordancia con la idea que poseían ciertos sectores de la aristocracia y de la burguesía -visión del servicio doméstico más ligada a la vieja servidumbre que realmente a una actividad profesional de mujeres de clases populares- que fueron incapaces de adaptarse a las nuevas modalidades del servicio doméstico, las trabajadoras discontinúas o a tiempo parcial, asistentas o interinas, las cuales despreciaban. Éstos vaticinaban que el servicio doméstico tradicional estaba en proceso de extinción debido al desarrollo económico que estaba experimentando la sociedad española. Ozores va más allá e hiperboliza este pensamiento en numerosas ocasiones a lo largo de la película. Una de las secuencias que contribuye a reforzar este imaginario, es aquella en la que una empleadora le usurpa la trabajadora del servicio doméstico a su amiga y comienzan una refriega. Según $\mathrm{ABC}$ estas conductas eran propias de ciudades como Nueva York, donde las empleadoras habían renunciado a vestir a las empleadas de hogar de uniforme, porque su identificación contribuía a que otras empleadoras se acercasen a ellas en la calle y les ofrecieran mejores condiciones y una nueva casa donde servir; por su puesto, el diario presentaba este «deporte femenino» como algo peregrino a la sociedad española. Aún así, Mariano persevera en 
esta idea cuando muestra cómo los empleadores con objeto de mantener a sus trabajadoras domésticas, terminan subordinándose a sus designios, incluso en una materia tan importante como el amor -el caso del médico que subordina sus sentimientos a los de su sirvienta-.

Para reforzar este pensamiento no duda en recurrir a la ironía. Comienza por un título retórico, "Cómo está el servicio", que sentencia un juicio de opinión un tanto desfavorable de las trabajadoras del sector. Continúa con una introducción histórica basada en el materialismo histórico marxista, que contrasta hábilmente con una última imagen donde se aprecia a Vicenta fumando y hablando por teléfono con toda tranquilidad en la casa donde sirve y contrariando a la empleadora. Esta escena muestra una imagen donde las trabajadoras asumen el control en las relaciones laborales y se imponen a las amas de casa, con intención de desmentir las voces que aún criticaban el servicio doméstico tradicional por considerarlo una subordinación humillante cercana a la esclavitud ${ }^{24}$. En el desarrollo de la película los empleadores son presentados como víctimas que sufren los caprichos y veleidades de sus empleadas de hogar; ello queda constatado por las numerosas veces que Vicenta cambia de casa con diferentes pretextos estúpidos y el guión ironiza poniendo en sus labios la siguiente frase: ¡Qué difícil está el servicio!.

Ozores demuestra un gran desconocimiento de la profesión del servicio doméstico y sus trabajadoras, y las escenifica siguiendo los tópicos tradicionales todavía existentes. Su representación en la esfera pública vestidas de uniforme requiere una profunda reflexión que deja en evidencia lo insostenible del argumento de esta película. Representar en espacios públicos a las trabajadoras del servicio doméstico con su indumentaria profesional no encaja bien con las innumerables manifestaciones de estas trabajadoras en cuanto a avergonzarse de su profesión y la ocultación que hacían de ella. Esta puesta en escena podría valer para épocas pretéritas pero no en el ocaso de la década desarrollista. Otro aspecto que incurre en fallo y apuntala la idea de no profesión es su escaso juicio sobre la previsión social de las empleadas del servicio doméstico. En 1969 el único seguro social de las empleadas de hogar existente y obligatorio era el Montepío Nacional del Servicio Doméstico, al cual Vicenta estaba afiliada. Por consiguiente el diálogo de Vicenta que aquí transcribimos, "que ganas tenía de servir en casa de un médico, así cada vez que me ponga enferma me saldrá gratis», está totalmente fuera de contexto, pues una vez afiliada, la cobertura sanitaria y los servicio médicos eran totalmente gratuitos. Como diría Peter Burke «La importancia de la distancia social o cultural resulta especialmente clara en aquellos casos en los que el artista o el fotógrafo es ajeno a la cultura que retrata ${ }^{25}$.

24 Un argumento similar compartía la película «The servant» de Joseph Losey producida en 1962 que retrataba el comportamiento tirano de los trabajadores del servicio doméstico británico.

25 P. Burke, Visto y no visto, op. cit. p. 153. 
Por su parte, Roberto Bodegas, al contrario que Ozores, se preocupa del trasfondo social que acompaña a este periodo de la historia española y refleja el servicio doméstico desde una visión interior, acudiendo a sus protagonistas y mostrando los problemas personales y emocionales de estas trabajadoras. Representa de manera intimista el drama social de la emigración que recae sobre estas empleadas, y es retratado como un proceso traumático. Esto, unido a una simbología muy cuidada, es una crítica consciente al régimen franquista que muestra los desequilibrios sociales del desarrollo económico y desmiente el discurso oficialista que hace de la progresión económica un gran triunfo de su política en todos los sentidos. Pone en evidencia las paradojas del desarrollo, que fuerza a la emigración a una parte de los españoles y origina la situación desesperada de otros que tienen que afrontarla por su cuenta y riesgo y fuera de los cauces legales del Instituto de Emigración Español. En este sentido también ilustra las miserias del desarrollo pues existen familias, como la de Paca, que no perciben las mejoras que el régimen alardea haber conseguido. La incipiente sociedad de consumo queda al margen de estas familias, pues su escaso poder adquisitivo hace que desconozcan y valoren como un regalo apreciado la importación de café que hace Paca desde Francia. El símbolo meditado del café y su ausencia es importante porque fue un producto muy cotizado durante los largos ańos de posguerra ${ }^{26}$, y sitúa a estas clases sociales en un nivel similar, subrayando de nuevo los contrastes del "progreso» económico y social. Bodegas remata esta crítica con un símbolo de mucha importancia. A través del regalo de la obra de Ortega y Gasset «España Invertebrada» que hace el economista a Emilia, introduce un paralelismo entre la crisis social, política y económica de principios de siglo XX descrita por el filósofo y la situación de crisis que considera padece el régimen, contrariando nuevamente los postulados oficiales ${ }^{27}$. Este trasfondo realista le hizo valedora del Premio Especial del Festival Internacional de Moscú. De puertas adentro, sin embargo, prevaleció el patriotismo y la exaltación de la españolidad frente a la crítica social, lo que le aportó numerosos galardones como fue el Premio del Sindicato Nacional del Espectáculo.

Además introduce una idea muy importante al considerar el servicio doméstico como un sector destacado que contribuye al desarrollo del país. Reconoce la importancia que tienen este grupo de trabajadoras, ya que cada una con su trabajo aporta una cantidad de divisas necesarias para el equilibrio de la balanza económica de España, lo que sitúa a las mujeres como sujetos activos y claves del desarrollo. Este pensamiento entra dentro de la corriente que a finales de los 50 comienza a extender el concepto de sujetos productivos a las trabajadoras del servicio doméstico, y empieza a distanciarse del carácter privado y familiar asignado tradicionalmente a esta ocupación y el sentido improductivo de sus trabajadoras.

$\overline{26}$ J. Eslava Galán, De la alpargata al seiscientos, op. cit.

27 Para un estudio de la importancia de la iconografía en el análisis histórico de las imágenes es clave la aportación de P. Burke, Visto y no visto, op. cit. pp. 43-57. 
En lo que a modelos de género se refiere, la proyección de Ozores reproduce los clásicos roles asignados a cada sexo, con lo que contribuye a perpetuar el ideal de la domesticidad femenina muy presente en la sociedad española. El objetivo final de toda mujer debe ser casarse y formar una familia, para dedicarse en cuerpo y alma al trabajo reproductivo y a las tareas del hogar. Como relataba un artículo de la revista N.C. de septiembre de 1960 «...Elisa -trabajadora del servicio doméstico- es una chica como tantas otras. Tiene veinte años, muchas ilusiones; desea que le salga un buen novio, casarse, tener su casa, guisar para su marido, cuidar de sus propios hijos...». Así es como termina la vida de Vicenta. Sin embargo Roberto Bodegas comienza tímidamente a introducir un cambio en los valores de género asignados a cada sexo. Tanto Isabel, la protagonista, como su paisana Emilia, comienzan siendo portadoras de los valores tradicionales que recaen sobre las mujeres y que son ilustrados en los sueńos enclaustrados de Emilia: desea casarse con un millonario, o resignarse siendo una sirvienta soltera al servicio de Francia -esta última opción era tan respetada como el celibato espiritual en una mujer, pues en definitiva seguía ligada al hogar y no contravenía el modelo tradicional de la domesticidad-. Estas primeras caracterizaciones de los personajes irán deshaciéndose en el transcurso de la película. En este sentido Emilia romperá de una manera radical este modelo y frente a la pasividad y la sumisión recomendada a las mujeres en cuestiones amorosas - «... a la mayoría de los hombres, les desilusiona el que las mujeres le vayan detrás. (...) Porque ahora, amigas mías, como hace un siglo y como hace diez, las mujeres han de permanecer en su sitio y esperar que sean los hombres quienes den los pasos necesarios. Por eso nada de allanarles el camino...» (revista N. C. septiembre 1960) -, ella llevará la iniciativa en sus múltiples relaciones. También dejará atrás las recomendaciones muy presentes en las revistas dirigidas a las trabajadoras del servicio doméstico de «ser chicas que no destaquen en la vestimenta y vayan sin pretensiones (...) porque la sencillez es lo que verdaderamente hace elegante y sin pretensiones a una mujer», pues el icono de la peluca es bastante clarividente. Bajo este modelo femenino tiene que renunciar a su nacionalidad y hacerse pasar por francesa, pues no encajaría bien con la idealizada idiosincrasia de las mujeres españolas. El modelo español era presentado de la siguiente manera "Es frecuente encontrar por esos mundos chicas con la cabeza oxidada por falta de uso y el corazón roto por exceso de ejercicio. No cabe en la mujer española una lección positiva al estilo de un bazar. Las iniciativas en estas latitudes quedan para el varón...» (revista N. C. agosto 1960). Como publicitara un anuncio sobre la película, esta actitud de Emilia era "el trasplante (...) a otra moral, a otra cultura, a otro concepto de vivir» (ABC 8-2-1970); aún así, y frente al destino negativo que le auguraría la ideología del ángel del hogar, termina por cambiar de oficio y ascender socialmente, lo que le supone una liberación y un paso a su independencia.

Isabel también contravendrá los clichés atribuidos a las mujeres dentro de la tradición cultural católica española. Decide ser madre soltera y no se avergüenza por ello, al 
contrario, lo lleva con orgullo y quedará plasmado en la secuencia donde registra el nacimiento en la embajada española aun no siendo necesario. Esta concienciación de criar a su hijo sola no le impide promocionar social y profesionalmente y ser económicamente independiente. Esta progresión social nuevamente es reflejada mediante un símbolo: su hijo será registrado con el mismo nombre que su hermano, figura de la progresión social de la familia García Laguna.

Estos dos films son muy importantes en el análisis histórico pues reflejan las distintas mentalidades existentes en una época determinada y sobre un hecho concreto. Como anticipamos anteriormente, el cine junto a otras fuentes, es una herramienta eficaz que bajo un examen rigurosamente crítico puede arrojar conocimiento histórico, como así ha sido, y nos ayuda a comprender mejor el desenvolvimiento de una sociedad y las diferentes tendencias dentro de ella. Así frente a pensamientos que comulgaban o no ponían en tela de juicio la cosmovisión de un régimen, identificados con las comedias landistas que estaban en sintonía con la despolitización propugnada por las altas esferas tecnócratas que deseaban una evolución hacia a una monarquía autoritaria, aparecieron otras expresiones que comenzaron a cuestionar la veracidad e idoneidad de esos modelos, socavando la unidad de pensamiento que intentó imponer el régimen antidemocrático y autoritario franquista sobre toda la sociedad. Unas buscaron la ruptura, como fue el caso de Viridiana de Luis Buñuel; otras, en cambio, dentro de la continuidad buscaron la disgregación, a través de la producción de relatos sociales morales-intimistas más que puramente críticos. Como afirmaría Bodegas «...No es una película deshonesta (...) Pienso que Españolas en París es (...) una película española, con las coordenadas del cine español, que intenta romper una serie de lugares comunes de un cine que se dice comercial. (...) Españolas en París responde a un país que no tiene partidos, que no tiene oposición legal...». Para afrontar esta situación de falta de libertades y soslayar la acción de la censura, se apoyó en las figuras femeninas para narrar la historia de la emigración, pues bajo el ideario franquista «la emigración de las mujeres no tiene responsabilidad social, su aventura es más bien psicológica y moral ${ }^{28}$. Las mujeres y su representación en el cine se convierte así en una herramienta eficaz y activa para cuestionar «la unidad de destino» de la dictadura del general Franco, y como vimos en la película de Bodegas, una vía útil para contrarrestar el discurso oficial triunfalista.

Para finalizar y como dijera Roberto Rossellini, uno de los máximos exponentes del nuevo realismo italiano, «El cine debería ser un medio como otro cualquiera, quizá más valioso que otros, de escribir la historia» y como la propia Historia, está expuesto a diferentes interpretaciones. Estas divergencias que hemos expuesto en líneas precedentes, como queda comprobado, no restan un ápice su valor histórico ${ }^{29}$.

28 A. Castro, El cine español en el banquillo, Fernando Torres Editor, Valencia, 1974.

29

P. Burke, Visto y no visto, op. cit. p.199. 